Relations industrielles

Industrial Relations

\title{
L'Entreprise et la Statistique, tome 2, par R. Dumas, Dunod,
} Paris, 1963, 295 pages.

\section{Bertrand Belzile}

Volume 19, numéro 1, janvier 1964

URI : https://id.erudit.org/iderudit/1021392ar

DOI : https://doi.org/10.7202/1021392ar

Aller au sommaire du numéro

Éditeur(s)

Département des relations industrielles de l’Université Laval

ISSN

0034-379X (imprimé)

1703-8138 (numérique)

Découvrir la revue

Citer ce compte rendu

Belzile, B. (1964). Compte rendu de [L'Entreprise et la Statistique, tome 2, par R. Dumas, Dunod, Paris, 1963, 295 pages.] Relations industrielles / Industrial

Relations, 19(1), 139-139. https://doi.org/10.7202/1021392ar

Tous droits réservés (C Département des relations industrielles de l’Université Laval, 1964
Ce document est protégé par la loi sur le droit d'auteur. L’utilisation des services d'Érudit (y compris la reproduction) est assujettie à sa politique d'utilisation que vous pouvez consulter en ligne.

https://apropos.erudit.org/fr/usagers/politique-dutilisation/ 
pas aux mêmes lois que la logique des calculs strictement comptables.

Cet ouvrage est bien fait pour ceux qui aiment à jouer avec des concepts, des hypothèses. Por des cheminements longs et ardus, ou bien il n'arrive à peu de chose, ou bien il aboutit à quelques conclusions valables qui sont de sens commun et très familières à tous ceux qui ont une expérience syndicale. Por ailleurs certaines de ses assertions sont plus que discutables. En voici un exemple: \&ll est difficile d'imaginer que la grève, échec pour les travailleurs considérés à titre individuel, soit une victoire pour le Syndicat, entité différente de ses membres \$. (p. 174) Si cela peut être vrai en courte période, il est assez facile de concevoir qu'en longue période il n'en est pos nécessairement ainsi.

L'ouvrage du professeur Mehling est remarquable par son souci d'objectivité. II n'a rien $d^{\prime}$ anti-syndical, mais il fera les délices de ceux qui, ne comprenant rien à l'action syndicale, trouvent toujours que ces groupements sont trop enclins à se lancer dans des oventures préjudiciables à leurs membres et à toute la communauté. J'hésiterais à le mettre entre les mains d'un dirigeant syndical qui aurait la patience de le prendre à la lettre et de le lire jusqu'au bout. Car, devant la multitude de questions qui restent sans réponse et l'incertitude des résultots dans une grève, ou bien ce dirigeant demeurerait toujours dans la perplexité et abandonnerait les travailleurs au bon vouloir des employeurs puissonts qui s'ocharneraient d̀ les tenir dans une situation d'injustice, ou bien il s'organiserait pour inciter les travailleurs à une action d'une telle violence que la grève ne serait pas de longue durée. $\mathrm{Ce}$ n'est certainement pas l'intention poursuivie par l'auteur.

Analyse socio-économique d'une grève est un livre utile. Préporé par un économiste sérieux et compétent, il illustre bien les difficultés que rencontre toute étude de ce phénomène économico-social qu'est la grève.

\section{L'Entreprise et la Statistique, tome 2, par} R. Dumos, Dunod, Paris, 1963, 295 poges.

II ne s'agit pas, loin de là, d'un manuel conventionnel de statistiques. L'auteur parle plutôt de l'information et de son traitement au sein de l'entreprise. II va même plus loin; i) situe certains problèmes majeurs qui se posent dans les entreprises modernes et développe des techniques d'analyse. La simple énumération des grands sujets traités nous permet de mieux voir le contenu du livre: la statistique et l'entreprise; le tableau de bord et les ratios; le contrôle des fabrications; la recherche opérotionnelle; l'étude du marché; la conjoncture; la statistique et la comptabilité; I'organisation d'un service statistique d'entreprise; des études de cas.

On pourrait dire que ce volume est une sorte d'introduction à divers sujets de l'administration de l'entreprise. L'auteur insiste toutefois sur les statistiques nécessaires à l'étude de ces sujets. Tel n'est pas le cas pour tous les sujets. La recherche opérotionnelle, por exemple, est analysée dans sa méthodologie même plutôt qu'en tant que statistiques à incorporer dans des modèles mathématiques; il s'ogit donc en l'occurence d'une sorte de très brève introduction da la recherche opérationnelle. Au contraire dans l'étude du marché, l'auteur ne fait pas seulement présenter une méthode de travail, mais mentionne plusieurs sortes de statistiques qui sont incluses dans de telles études.

Qui ce livre peut-il intéresser? Nous croyons que les hommes d'affaires soucieux d'améliorer la gestion de leurs entreprises pourraient retirer profit de la lecture de «L'Entreprise et la Statistique ». Nous en conseillons également la lecture aux administrateurs qui ont besoin de connaître les différentes techniques d'analyse des problèmes des entreprises. Nous ne croyons pas qu'il puisse intéresser les spécialistes de la gestion, car l'exposé des divers sujels ne va pas assez en profondeur.

Bertrand Belzile

\section{RELATIONS INDUSTRIELLES}

volume 18

\section{S O M M A I R E}

Index bibliographique - Cumulative Index. REVUE Relations industrielles Industrial Relations, REVIEW volume 1-18 (1945-1963) Rapports des Proceedings of Congrès des Relations industrielles (1946-1963) Index Volume 18 - 1963. 